\title{
Case Report \\ Leisure Agricultural Park Selection for Traveler Groups Amid the COVID-19 Pandemic
}

\author{
Hsin-Chieh $\mathrm{Wu}^{1}{ }^{1}, \mathrm{Yu}-\mathrm{Cheng} \operatorname{Lin}^{2}$ and Tin-Chih Toly Chen ${ }^{3, *}$ \\ 1 Department of Industrial Engineering and Management, Chaoyang University of Technology, \\ Taichung City 413310, Taiwan; hcwul@cyut.edu.tw \\ 2 Department of Computer-Aided Industrial Design, Overseas Chinese University, Taichung City 40721, \\ Taiwan; yclin@ocu.edu.tw \\ 3 Department of Industrial Engineering and Management, National Yang Ming Chiao Tung University, \\ Hsinchu City 30010, Taiwan \\ * Correspondence: tcchen@nycu.edu.tw
}

Citation: Wu, H.-C.; Lin, Y.-C.; Chen, T.-C.T. Leisure Agricultural Park

Selection for Traveler Groups Amid the COVID-19 Pandemic. Agriculture 2022, 12, 111. https://doi.org/ 10.3390/agriculture12010111

Academic Editor: Dimitre Dimitrov

Received: 20 December 2021

Accepted: 12 January 2022

Published: 13 January 2022

Publisher's Note: MDPI stays neutral with regard to jurisdictional claims in published maps and institutional affiliations.

Copyright: (C) 2022 by the authors. Licensee MDPI, Basel, Switzerland. This article is an open access article distributed under the terms and conditions of the Creative Commons Attribution (CC BY) license (https:// creativecommons.org/licenses/by/ $4.0 /)$.

\begin{abstract}
With the widespread vaccination against COVID-19, people began to resume regional tourism. Outdoor attractions, such as leisure agricultural parks, are particularly attractive because they are well ventilated and can prevent the spread of COVID-19. However, during the COVID-19 pandemic, the considerations around choosing a leisure agricultural park are different from usual, and will be affected by uncertainty. Therefore, this research proposes a fuzzy collaborative intelligence (FCI) approach to help select leisure agricultural parks suitable for traveler groups during the COVID19 pandemic. The proposed FCI approach combines asymmetrically calibrated fuzzy geometric mean (acFGM), fuzzy weighted intersection (FWI), and fuzzy Vise Kriterijumska Optimizacija I Kompromisno Resenje (fuzzy VIKOR), which is a novel attempt in this field. The effectiveness of the proposed FCI approach has been verified by a case study in Taichung City, Taiwan. The results of the case study showed that during the COVID-19 pandemic, travelers (especially traveler groups) were very willing to go to leisure agricultural parks. In addition, the most important criterion for choosing a suitable leisure agricultural park was the ease of maintaining social distance, while the least important criterion was the distance from a leisure agricultural park. Further, the successful recommendation rate using the proposed methodology was as high as $90 \%$.
\end{abstract}

Keywords: leisure agricultural park; traveler group; COVID-19 pandemic; fuzzy collaborative intelligence

\section{Introduction}

In the late stage of the COVID-19 pandemic, with the popularity of vaccination, domestic tourism gradually recovered. When choosing tourist attractions, some regulations on the prevention of the COVID-19 pandemic are still influential [1]; for example, many tourists tend to choose attractions that are health-oriented, have a relatively mild pandemic, make it easy to maintain social distance, and are well ventilated (to avoid wearing masks for a long time) [2]. These considerations are different to those before the COVID-19 pandemic, when consumers valued the quality of agricultural products [3], the convenience of onsite consumption, the distance from downtown [4], the availability of auxiliary facilities, etc. [5-7]. In addition, many current considerations are quite uncertain [8-10]; for example, whether it is easy to maintain social distance is affected by the number of people entering the park, and it also depends on the control measures of the leisure agricultural park. Furthermore, if all visitors in the park wear masks, good ventilation is not as important. As a result, selecting or recommending a suitable leisure agricultural park has become a challenging task. The motivation of this research is to accomplish this task.

Some relevant references are henceforth reviewed. According to Pan et al. [11], the COVID-19 pandemic has impacted eight major aspects of the agricultural economy, one of 
which is leisure agriculture. In the view of Ateljevic [12], the normalization of the COVID19 pandemic on the tourism system may have an impact on regenerative agriculture and transitional tourism. According to statistics supplied by Putian [13], the impact of the COVID-19 pandemic on leisure agriculture includes a substantial reduction in revenues, a reduction in advertising budgets, difficulties in resuming production, unsmooth sales channels, and declining consumer demand. The results of the study by Barrot et al. [14] showed that leisure and agriculture were industries in which employment rates have fallen sharply due to the COVID-19 pandemic. Therefore, Li et al. [4] believed that under the premise that the COVID-19 pandemic can be prevented and controlled, it is the responsibility of the local government to take effective and efficient measures to restore leisure agriculture. Further, in the view of Hsiao and Tuan [10], the dynamic ability of leisure agriculture park operators to change park marketing channels and develop new products or services to respond to the new market can effectively respond to the COVID-19 pandemic. The COVID-19 pandemic has also caused labor shortages in many agricultural activities. This led to a sharp rise in short-term labor wages and increased the burden on farm operators [15]. Leisure agriculture, which allows customers to pick agricultural products by themselves, is a solution. Some studies also concluded that the COVID-19 pandemic has caused suburban agriculture to be replaced by leisure agriculture and other land applications with higher market value [16]. All in all, most past studies have shown that leisure agricultural park operators or employees are facing challenges, but these studies have not explored the difficulties faced by travelers who plan to visit these parks. This study can make up for this deficiency.

To recommend suitable leisure agricultural parks for traveler groups amid the COVID19 pandemic, a fuzzy collaborative intelligence (FCI) approach is proposed in this study. The reason for adopting a fuzzy approach is to consider the uncertainty brought about by the COVID-19 pandemic. The reason for discussing traveler groups (or group tours) is because the customers of a leisure agricultural park are mostly families. Different family members may have different considerations in choosing a suitable leisure agricultural park, affecting the formation of a consensus among them. FCI is a viable means to solve this problem.

The contribution of this study includes the following:

(1) After the outbreak of the COVID-19 pandemic, the factors affecting travelers visiting a leisure agricultural park have been different to the previous factors. In addition to subjective personal preferences, there is also objective information related to the COVID-19 pandemic. This study is one of the first studies to explore the influence of these factors on travelers' decisions in choosing suitable leisure agricultural parks.

(2) The acFGM method is proposed to enhance the precision of deriving the priorities of factors critical to the selection of a suitable leisure agricultural park.

The remainder of this paper is organized as follows: Section 2 is an introduction of the FCI approach proposed in this study; Section 3 details the application of the FCI approach to a case study in Taichung City, Taiwan, amid the COVID-19 pandemic; Section 4 provides the conclusions of this study, as well as some possible topics for future investigation.

\section{Methodology}

Without loss of generality, all fuzzy parameters and variables in the proposed methodology are given in or approximated by triangular fuzzy numbers (TFNs). At first, the asymmetrically calibrated fuzzy geometric mean (acFGM) method is proposed for decision makers to derive the fuzzy priorities of criteria that affect their choices.

\section{1. acFGM for Deriving the Fuzzy Priorities of Criteria}

In the beginning, every decision maker is asked to make pairwise comparisons of the relative priorities of criteria. The results by decision maker $k$ are inserted into the following 
fuzzy judgment matrix: $\widetilde{\mathbf{A}}(k)=\left\{\widetilde{a}_{i j}(k)\right\}$ where $\widetilde{a}_{i j}(k)$ are fuzzy sets; $i, j=[1, n] ; k=1 \sim K$. The following is true according to Satty [17]:

$$
\begin{gathered}
\operatorname{det}(\widetilde{\mathbf{A}}(k)(-) \widetilde{\lambda}(k) \mathbf{I})=0 \\
(\widetilde{\mathbf{A}}(k)(-) \widetilde{\lambda}(k))(\times) \widetilde{\mathbf{x}}(k)=0
\end{gathered}
$$

where $\widetilde{\lambda}(k)$ and $\widetilde{\mathbf{x}}(k)$ are the fuzzy eigenvalue and fuzzy eigenvector of $\widetilde{\mathbf{A}}(k)$, respectively; $(-)$ and $(x)$ denote fuzzy subtraction and multiplication, respectively. Equations (1) and (2) involve fuzzy multiplication operations, making it difficult to derive the exact values of $\widetilde{\lambda}(k)$ and $\widetilde{\mathbf{x}}(k)$. Fuzzy geometric mean (FGM) is a prevalent method to approximate the solution [18]. However, the accuracy of deriving the fuzzy priorities of criteria using FGM is not always high. To solve this problem, Chen and Wang [19] proposed the calibrated FGM (cFGM) method to improve the accuracy in an efficient manner. The cFGM method has the following steps:

Step 1. Approximate the value of the fuzzy priority of criterion $i$ using FGM as in the following [18]:

$$
\widetilde{w}_{i}(k) \cong\left(w_{i 1}(k), w_{i 2}(k), w_{i 3}(k)\right)
$$

where the following applies:

$$
\begin{gathered}
w_{i 1}(k)=\frac{1}{1+\sum_{m \neq i} \frac{\sqrt[n]{\prod_{j=1}^{n} a_{m j 3}(k)}}{\sqrt[n]{\prod_{j=1}^{n} a_{i j 1}(k)}}} \\
w_{i 2}(k) \cong \frac{1}{1+\sum_{m \neq i} \frac{\sqrt[n]{\prod_{j=1}^{n} a_{m j 2}(k)}}{\sqrt[n]{\prod_{j=1}^{n} a_{i j 2}(k)}}} \\
w_{i 3}(k) \cong \frac{1}{1+\sum_{m \neq i} \frac{\sqrt[n]{\prod_{j=1}^{n} a_{m j 1}(k)}}{\sqrt[n]{\prod_{j=1}^{n} a_{i j 3}(k)}}}
\end{gathered}
$$

$\widetilde{w}_{i}(k)$ is the fuzzy priority of criterion $i$ to decision maker $k$.

Step 2. Derive the priority of criterion $i$ from the crisp judgment matrix $\mathbf{A}^{c}(k)=\left[a_{i j 2}(k)\right]$ using an eigen analysis, as in the following [17]:

$$
\begin{gathered}
\operatorname{det}\left(\mathbf{A}^{c}(k)-\lambda^{c}(k) \mathbf{I}\right)=0 \\
\left(\mathbf{A}^{c}(k)-\lambda^{c}(k) \mathbf{I}\right) \mathbf{x}^{c}(k)=0 \\
w_{i}^{c}(k)=\frac{x_{i}^{c}}{\sum_{j=1}^{n} x_{j}^{c}}
\end{gathered}
$$

The derived priority is indicated with $w_{i}^{c}(k)$.

Step 3. Calibrate the fuzzy priority of criterion $i$ in the following way:

$$
\begin{aligned}
w_{i 1}(k) \rightarrow & w_{i 1}(k)+w_{i}^{c}(k)-w_{i 2}(k) \\
& w_{i 2}(k) \rightarrow w_{i}^{c}(k) \\
w_{i 3}(k) \rightarrow & w_{i 3}(k)+w_{i}^{c}(k)-w_{i 2}(k)
\end{aligned}
$$


However, the cFGM method has the following problems:

(1) After calibration, $w_{i 1}(k)$ may be negative, which is infeasible.

(2) The range of a fuzzy priority approximated using FGM is usually wider than that of the actual value, which is not considered in the calibration process.

To solve these problems, the acFGM method is proposed, as in the following:

$$
\begin{aligned}
& w_{i 1}(k) \rightarrow \max \left(w_{i 1}(k)+w_{i}^{c}(k)-w_{i 2}(k), w_{i 1}(k) \cdot \frac{w_{i}^{c}(k)}{w_{i 2}(k)}\right) \\
& w_{i 3}(k) \rightarrow \min \left(w_{i 3}(k)+w_{i}^{c}(k)-w_{i 2}(k), w_{i 3}(k) \cdot \frac{w_{i}^{c}(k)}{w_{i 2}(k)}\right)
\end{aligned}
$$

The results using various methods are compared in Figure 1.

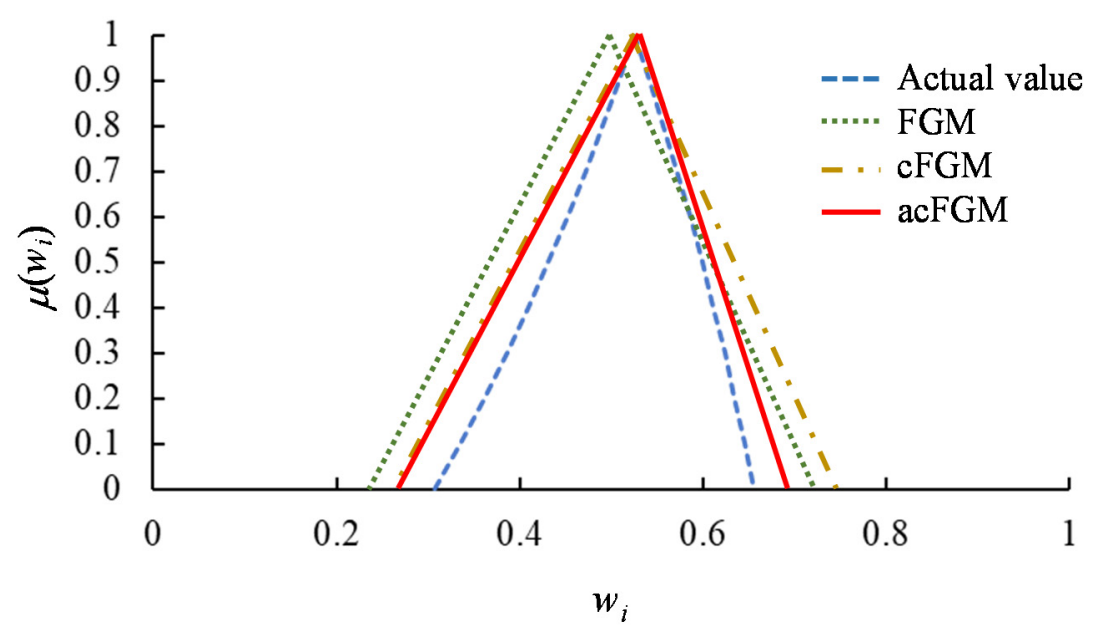

Figure 1. Comparison of the results using various methods.

The fuzzy priorities of a criterion derived by different decision makers are not the same, and need to be aggregated. In addition, some decision makers are more authoritative than others. To consider these, fuzzy weighted intersection (FWI) [20] is applied, as described in the next section.

\subsection{FWI for Aggregating the Fuzzy Priorities of Criteria Derived by All Decision Makers}

Most of the existing methods aggregate the fuzzy priorities of a criterion derived by all decision makers using fuzzy arithmetic average operators [21-23] and fuzzy geometric mean operators [21-23]. The only difference is the type of fuzzy numbers. However, the aggregation result may be unreasonable [20]. In particular, the aggregation result may be a value with low membership in the fuzzy priority of each decision maker.

In the proposed methodology, FWI [20] is applied to aggregate the fuzzy priorities of a criterion derived by all decision makers, as in the following:

$$
\widetilde{w}_{i}(\text { all })=\widetilde{F W I}\left(\left\{\widetilde{w}_{i}(k)\right\}\right)
$$

with the following membership function:

$$
\mu_{\widetilde{w}_{i}(a l l)}(x)=\min _{k} \mu_{\widetilde{w}_{i}(k)}(x)+\sum_{k}\left(\omega_{k}-\min _{l} \omega_{l}\right)\left(\mu_{\widetilde{w}_{i}(k)}(x)-\min _{l} \mu_{\widetilde{w}_{i}(l)}(x)\right)
$$

where $\omega_{k}$ is the authority level of decision maker $k ; \sum^{K} \omega_{k}=1$. An example is provided in Figure 2, in which the authority levels of the three $\mathrm{d}^{\mathrm{d}}$ ecision makers are $0.35,0.15$, and 0.5 , respectively. The aggregation result is not an empty set, despite the fact that decision makers may lack an overall consensus, as illustrated by Figure 3. 

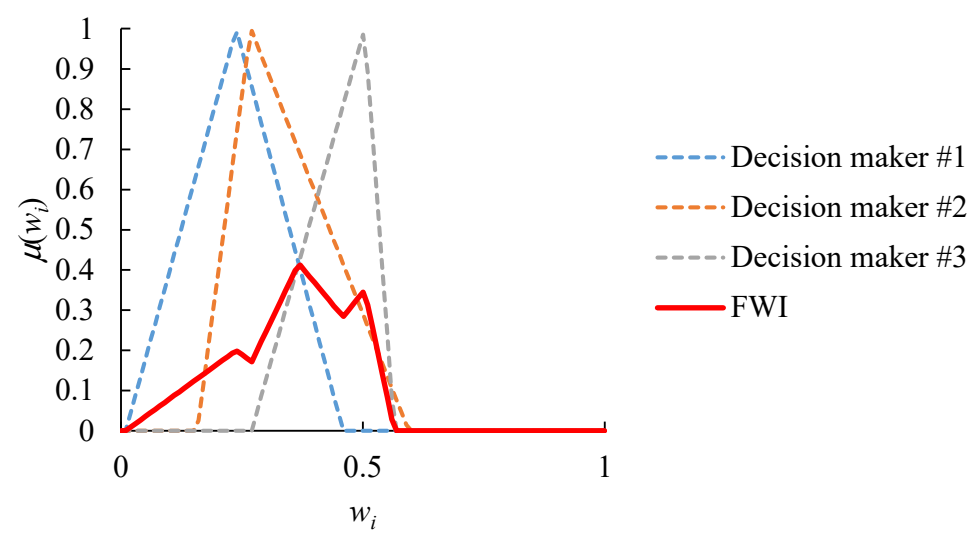

Figure 2. An FWI example.
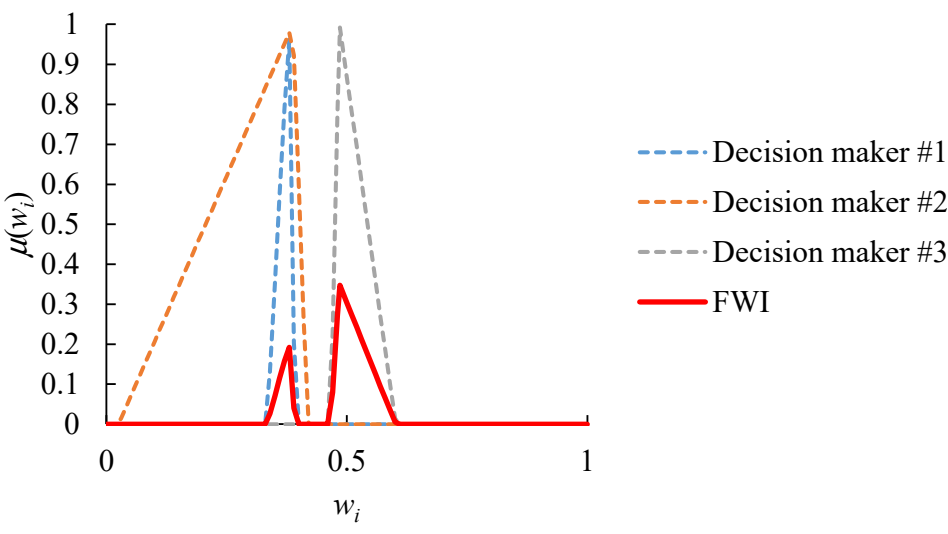

Figure 3. The aggregation result when decision makers lack an overall consensus.

The FWI operator meets the following conditions [20]:

(1) $\widetilde{F W I}\left(\left\{\widetilde{w}_{i}(k)\right\}\right)=\widetilde{w}_{i}(l)$ if $\omega_{l}=1$ and $\omega_{k}=0 \forall k \neq l$

(2) $\widetilde{F W I}\left(\left\{\widetilde{w}_{i}(k)\right\}\right)=\widetilde{F I}\left(\left\{\widetilde{w}_{i}(k)\right\}\right)$ if $\omega_{k}=\frac{1}{K} \forall k ; \widetilde{F I}$ is the fuzzy intersection operator (i.e., the $t$-norm).

(3) $\min _{l} \mu_{\widetilde{w}_{i}(l)}(x) \leq \mu_{\widetilde{F W I}\left(\left\{\widetilde{w}_{i}(k)\right\}\right)}(x) \leq \max _{l} \mu_{\widetilde{w}_{i}(l)}(x)$

(4) $\frac{\partial \mu_{\widetilde{F W I}\left(\left\{\tilde{w}_{i}(k)\right\}\right)}(x)}{\partial \mu_{\widetilde{w}_{i}}(l)} \propto \omega_{l}$

Aggregating the fuzzy priorities of a criterion derived by all decision makers using FWI guarantees that values considered highly possible by all decision makers or just the most authoritative decision maker will have high memberships in the aggregation result. In other words, the aggregation result will be more in line with the expectations of all decision makers, and it will be easier for everyone to accept.

One problem with the FWI operator is the polygonal shape of the aggregation result, which increases the computational complexity of subsequent operations. To overcome this difficulty, Wu et al. [24] advised that the aggregation result should be approximated with a TFN, such that their defuzzification results using the center-of-gravity (COG) method [25] are equal, as in the following:

$$
\begin{aligned}
\widetilde{F W I}\left(\left\{\widetilde{w}_{i}(k)\right\} \cong\right. & \left(\operatorname { m i n } \left(\widetilde{F W I}\left(\left\{\widetilde{w}_{i}(k)\right\}\right),\right.\right. \\
& 3 \operatorname{COG}\left(\widetilde{F W I}\left(\left\{\widetilde{w}_{i}(k)\right\}\right)-\max \left(\widetilde{F W I}\left(\left\{\widetilde{w}_{i}(k)\right\}\right)-\min \left(\widetilde{F W I}\left(\left\{\widetilde{w}_{i}(k)\right\}\right),\right.\right.\right. \\
& \max \left(\widetilde{F W I}\left(\left\{\widetilde{w}_{i}(k)\right\}\right)\right.
\end{aligned}
$$


where the following applies:

$$
\operatorname{COG} \widetilde{F W I}\left(\left\{\widetilde{w}_{i}(k)\right\}\right)=\frac{\int_{\text {all } x} x \mu_{\widetilde{F W I}}\left(\left\{\widetilde{w}_{i}(k)\right\}\right.}{\int_{\text {all } x} \mu_{\widetilde{F W I}\left(\left\{\widetilde{w}_{i}(k)\right\}\right.}(x) d x}
$$

An example is shown in Figure 4.
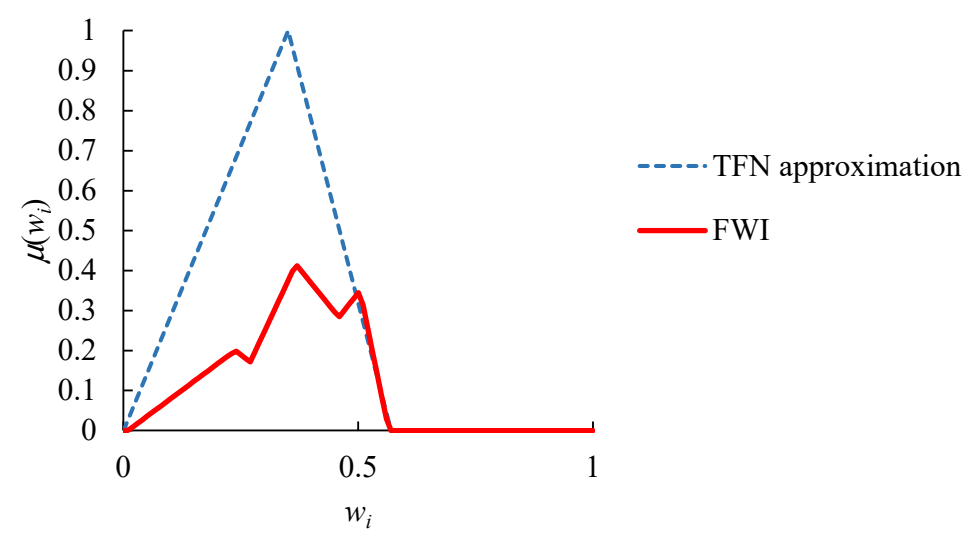

-FWI

Figure 4. Approximating the aggregation result with a TFN.

\subsection{Fuzzy VIKOR for Evaluating Alternatives}

Subsequently, the fuzzy Vise Kriterijumska Optimizacija I Kompromisno Resenje (fuzzy VIKOR) method $[26,27]$ is applied to evaluate the overall performance of each alternative. The fuzzy VIKOR method comprises the following steps:

Step 1. Determine the best and worst values of each criterion, as in the following:

$$
\begin{aligned}
\tilde{p}_{i}^{*} & =\max _{h} \widetilde{p}_{h i} \\
& =\left(\max _{h} p_{h i 1}, \max _{h} p_{h i 2}, \max _{h} p_{h i 3}\right) \\
\widetilde{p}_{i}^{-} & =\min _{h} \widetilde{p}_{h i} \\
& =\left(\min _{h} p_{h i 1}, \min _{h} p_{h i 2}, \min _{h} p_{h i 3}\right)
\end{aligned}
$$

where $\widetilde{p}_{h i}$ is the performance of alternative $h$ in optimizing criterion $i . ; h=1 \sim H . \widetilde{p}_{i}^{*}$ and $\widetilde{p}_{i}^{-}$ indicate the best and worst performances in optimizing criteria $i$, respectively.

Step 2. Compute normalized fuzzy distances, as in the following:

$$
\begin{aligned}
\widetilde{d}_{h i} & =\frac{\widetilde{p}_{i}^{*}(-) \tilde{p}_{h i}}{p_{i 3}^{*}-p_{i 1}^{-}} \\
& =\left(\frac{p_{i 1}^{*}-p_{h i 3}}{p_{i 3}^{*}-p_{i 1}^{-}}, \frac{p_{i 2}^{*}-p_{h i 2}}{p_{i 3}^{*}-p_{i 1}^{-}}, \frac{p_{i 3}^{*}-p_{h i 1}}{p_{i 3}^{*}-p_{i 1}^{-}}\right)
\end{aligned}
$$

Step 3. Compute the values of $\widetilde{S}_{h}$ and $\widetilde{R}_{h}$ [28], as in the following:

$$
\begin{aligned}
\widetilde{S}_{h} & =\sum_{i=1}^{n}\left(\widetilde{w}_{i}(\text { all })(\times) \widetilde{d}_{h i}\right) \\
\widetilde{R}_{h} & =\max _{i}\left(\widetilde{w}_{i}(\text { all })(\times) \widetilde{d}_{h i}\right)
\end{aligned}
$$

$\widetilde{S}_{h}$ considers the performances of alternative $h$ in optimizing all criteria, while $\widetilde{R}_{h}$ highlights the performance of the alternative in optimizing the most important criterion or the worse performance. 
Step 4. Compute the value of $\widetilde{Q}_{h}$ [28], as in the following:

$$
\widetilde{Q}_{h}=\xi \cdot \frac{\widetilde{S}_{h}(-) \min _{r} \widetilde{S}_{r}}{\max \left(\max _{r} \widetilde{S}_{r}\right)-\min \left(\min _{r} \widetilde{S}_{r}\right)}(+)(1-\xi) \cdot \frac{\widetilde{R}_{h}(-) \min _{r} \widetilde{R}_{r}}{\max \left(\max _{r} \widetilde{R}_{r}\right)-\min \left(\min _{r} \widetilde{R}_{r}\right)}
$$

where $\xi \in[0,1]$.

Step 5. Defuzzify $\widetilde{S}_{h}, \widetilde{R}_{h}, \widetilde{Q}_{h}$ using the COG method, as in the following:

$$
\begin{aligned}
& \operatorname{COG}\left(\widetilde{S}_{h}\right)=\frac{\int \text { all } x}{\int_{\text {all } x} x \mu_{\widetilde{S}_{h}}(x) d x} \\
& \operatorname{COG}\left(\widetilde{R}_{h}\right)=\frac{\int_{\text {all } x} x \mu_{\widetilde{R}_{h}}(x) d x}{\int_{\text {all } x} \mu_{\widetilde{R}_{h}}(x) d x} \\
& \operatorname{COG}\left(\widetilde{Q}_{h}\right)=\frac{\int_{\text {all } x} x \mu_{\widetilde{Q}_{h}}(x) d x}{\int_{\text {all } x} \mu_{\widetilde{Q}_{h}}(x) d x}
\end{aligned}
$$

Step 6. Rank alternatives according to their $D\left(\widetilde{S}_{h}\right), D\left(\widetilde{R}_{h}\right)$, and $D\left(\widetilde{Q}_{h}\right)$ values from the smallest to the largest. The decision maker will have three ranking results, giving him/her a high degree of flexibility, which is an advantage of fuzzy VIKOR over fuzzy technique for order preference by similarity to ideal solution (FTOPSIS) [29,30]; for example, when $D\left(\widetilde{Q}_{h}\right)$ is considered, the top two alternatives are indicated with alternatives $h_{(1)}$ and $h_{(2)}$, respectively. Then, in the view of Opricovic [28], alternative $h_{(1)}$ can be recommended to the decision maker if the following two conditions are met:

$$
\begin{gathered}
D\left(\widetilde{Q}_{h_{(2)}}\right)-D\left(\widetilde{Q}_{h_{(1)}}\right) \geq \frac{1}{H-1} \\
D\left(\widetilde{S}_{h_{(1)}}\right)=\min _{r} D\left(\widetilde{S}_{r}\right) \text { or } D\left(\widetilde{R}_{h_{(1)}}\right)=\min _{r} D\left(\widetilde{R}_{r}\right)
\end{gathered}
$$

\section{Case Study}

\subsection{Background}

To validate the effectiveness of the proposed methodology, a standalone leisure agricultural park recommendation system has been developed using Microsoft Access 2019 on a PC with an i7-7700 CPU $2723.6 \mathrm{GHz}$ and 16 GB RAM, and installed in a travel agency in Taichung City, Taiwan. The following five criteria were considered in building the recommendation mechanism encoded using VBA: the image of the leisure agricultural park, the number of confirmed COVID-19 cases in the city, the easiness of maintaining social distance, the distance to the leisure agricultural park, and the preference for agricultural products or natural facilities in the leisure agricultural park. During August 2021, a total of 10 traveler groups used this system to seek recommendations for suitable leisure agricultural parks. In this case study, the first traveler group is taken as an example to illustrate the application of the proposed methodology.

\subsection{Application of the Proposed Methodology}

The first few steps of the proposed methodology are a fuzzy analytic hierarchy process (FAHP). FAHP is the incorporation of fuzzy logic into an analytic hierarchy process (AHP), which is a well-known multi-criteria decision-making method based on the pairwise comparison of criteria [17]. The prevalent methods for solving an FAHP problem include FGM [18], fuzzy extent analysis (FEA) [31], and alpha-cut operations (ACO) [32,33]. 
Fuzzy AHP methods have been widely applied to multi-criteria decision making in agriculture [34-37].

The first traveler group was a family composed of the following three members (i.e., decision makers): father, mother, and daughter. Each decision maker compared the priorities of criteria in pairs. The results are summarized by the following fuzzy judgment matrixes:

$$
\begin{aligned}
\widetilde{\mathbf{A}}(1) & =\left[\begin{array}{ccccc}
1 & (2,4,6) & 1 /(1,1,3) & (2,4,6) & (2,4,6) \\
1 /(2,4,6) & 1 & 1 /(3,5,7) & (1,1,3) & 1 /(3,5,7) \\
(1,1,3) & (3,5,7) & 1 & (3,5,7) & (2,4,6) \\
1 /(2,4,6) & 1 /(1,1,3) & 1 /(3,5,7) & 1 & 1 /(2,4,6) \\
1 /(2,4,6) & (3,5,7) & 1 /(2,4,6) & (2,4,6) & 1
\end{array}\right] \\
\widetilde{\mathbf{A}}(2) & =\left[\begin{array}{ccccc}
1 & (3,5,7) & (1,3,5) & (3,5,7) & (1,3,5) \\
1 /(3,5,7) & 1 & 1 /(2,4,6) & (2,4,6) & 1 /(3,5,7) \\
1 /(1,3,5) & (2,4,6) & 1 & (2,4,6) & (1,3,5) \\
1 /(3,5,7) & 1 /(2,4,6) & 1 /(2,4,6) & 1 & 1 /(3,5,7) \\
1 /(1,3,5) & (3,5,7) & 1 /(1,3,5) & (3,5,7) & 1
\end{array}\right] \\
\widetilde{\mathbf{A}}(3) & =\left[\begin{array}{ccccc}
1 & (2,4,6) & 1 /(1,3,5) & (3,5,7) & (1,3,5) \\
1 /(2,4,6) & 1 & 1 /(2,4,6) & (1,3,5) & 1 /(1,3,5) \\
(1,3,5) & (2,4,6) & 1 & (2,4,6) & (1,3,5) \\
1 /(3,5,7) & 1 /(1,3,5) & 1 /(2,4,6) & 1 & 1 /(2,4,6) \\
1 /(1,3,5) & (1,3,5) & 1 /(1,3,5) & (2,4,6) & 1
\end{array}\right]
\end{aligned}
$$

The fuzzy priorities of criteria were derived from the fuzzy judgment matrixes using the acFGM method. The results are summarized in Table 1. The fuzzy priorities of criteria are compared in Figure 5. The fuzzy consistency ratios of these fuzzy judgment matrixes were all less than 0.1 , showing that they were consistent.
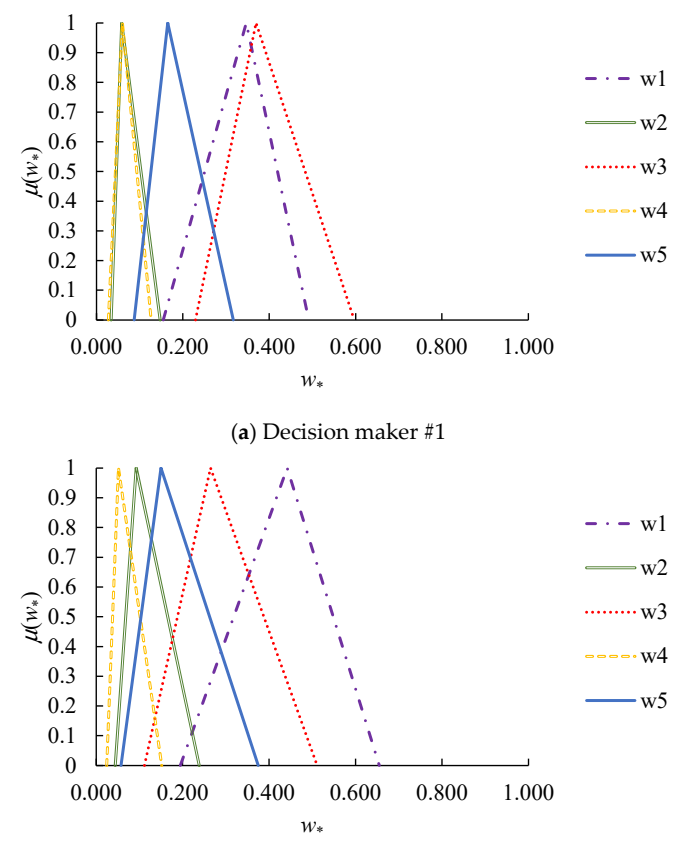

(b) Decision maker \#2

Figure 5. Cont. 


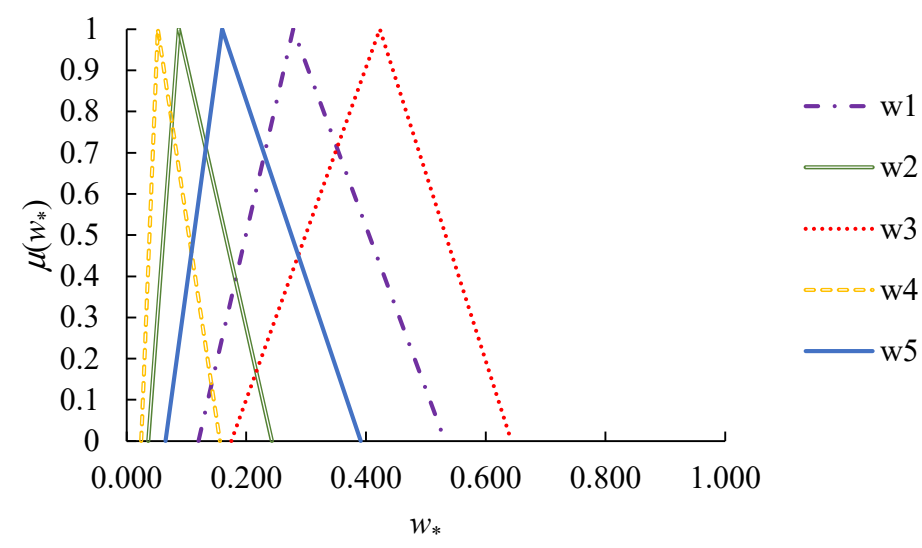

(c) Decision maker \#3

Figure 5. Comparison of the fuzzy priorities of criteria.

Table 1. Fuzzy priorities of criteria derived by all decision makers.

\begin{tabular}{cccc}
\hline $\boldsymbol{i}$ & $\widetilde{\boldsymbol{w}}_{\boldsymbol{i}}(1)$ & $\widetilde{\boldsymbol{w}}_{\boldsymbol{i}}(2)$ & $\widetilde{\boldsymbol{w}}_{\boldsymbol{i}}(3)$ \\
\hline 1 & $(0.155,0.347,0.491)$ & $(0.195,0.442,0.655)$ & $(0.12,0.278,0.532)$ \\
\hline 2 & $(0.034,0.059,0.147)$ & $(0.044,0.092,0.238)$ & $(0.036,0.087,0.243)$ \\
\hline 3 & $(0.229,0.369,0.596)$ & $(0.112,0.264,0.511)$ & $(0.175,0.423,0.643)$ \\
\hline 4 & $(0.027,0.06,0.127)$ & $(0.024,0.051,0.151)$ & $(0.024,0.052,0.156)$ \\
\hline 5 & $(0.087,0.165,0.316)$ & $(0.057,0.15,0.375)$ & $(0.065,0.159,0.391)$ \\
\hline
\end{tabular}

Subsequently, FWI [38-42] was applied to aggregate the fuzzy priorities derived by all decision makers. The authority levels of the decision makers were subjectively determined by them jointly as 0.5 (father), 0.2 (mother), and 0.3 (daughter), respectively. The aggregation results are shown in Figure 6.

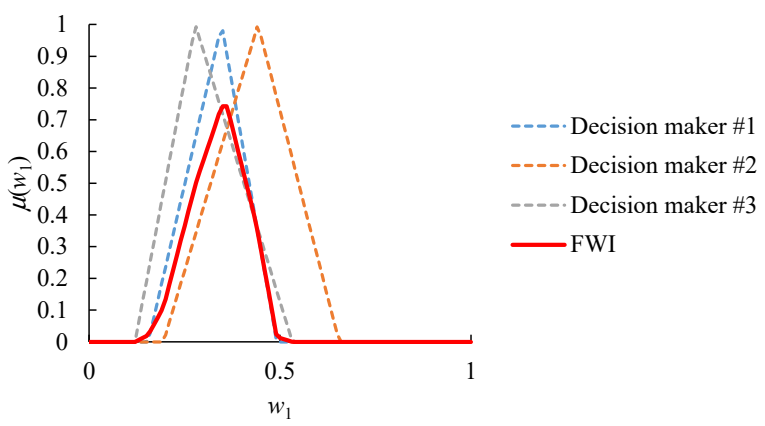

(a) The aggregation result of $\widetilde{w}_{1}$

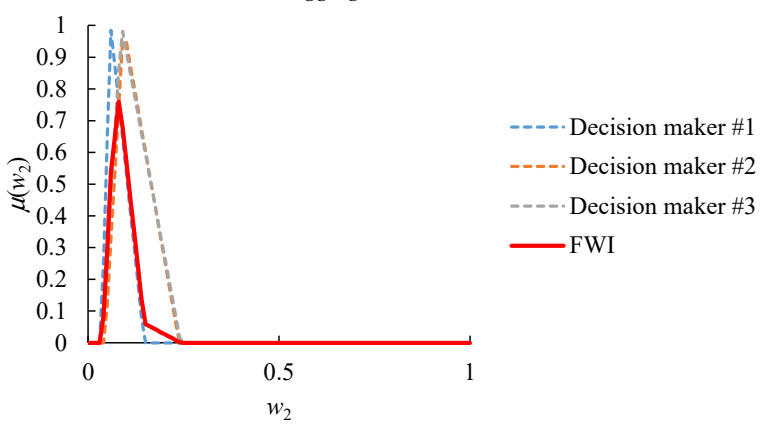

(b) The aggregation result of $\widetilde{w}_{2}$

Figure 6. Cont. 


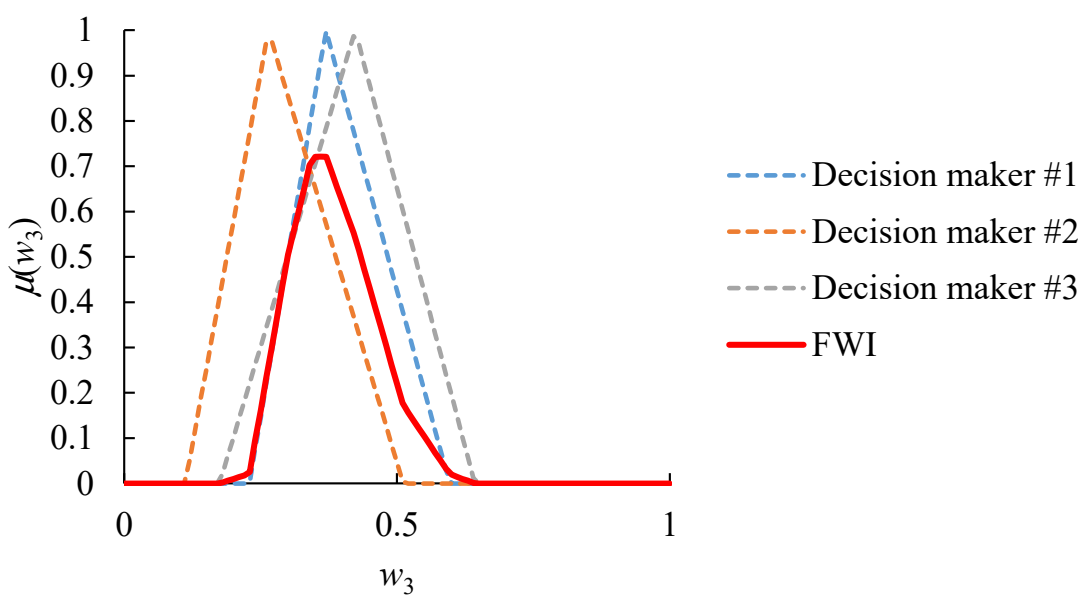

(c) The aggregation result of $\widetilde{w}_{3}$

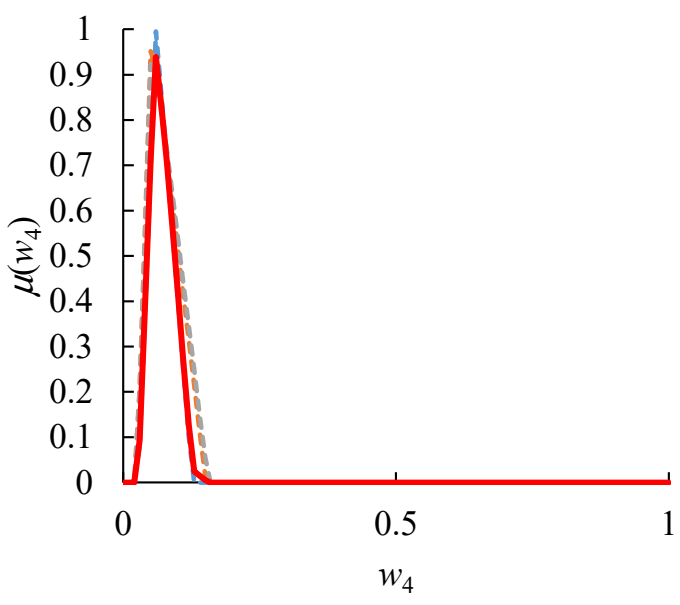

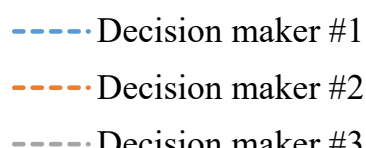

$\longrightarrow$ FWI

(d) The aggregation result of $\widetilde{w}_{4}$

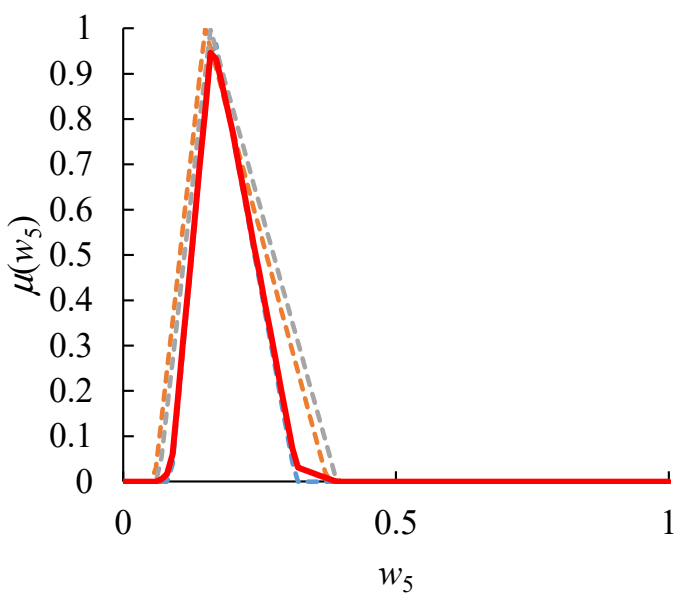

----.-Decision maker \#1

- - - Decision maker \#2

- - - Decision maker \#3

$\longrightarrow$ FWI

(e) The aggregation result of $\widetilde{w}_{5}$

Figure 6. Aggregation results.

To facilitate subsequent operations, the polygonal aggregation result was approximated with a TFN, as shown in Figure 7. 


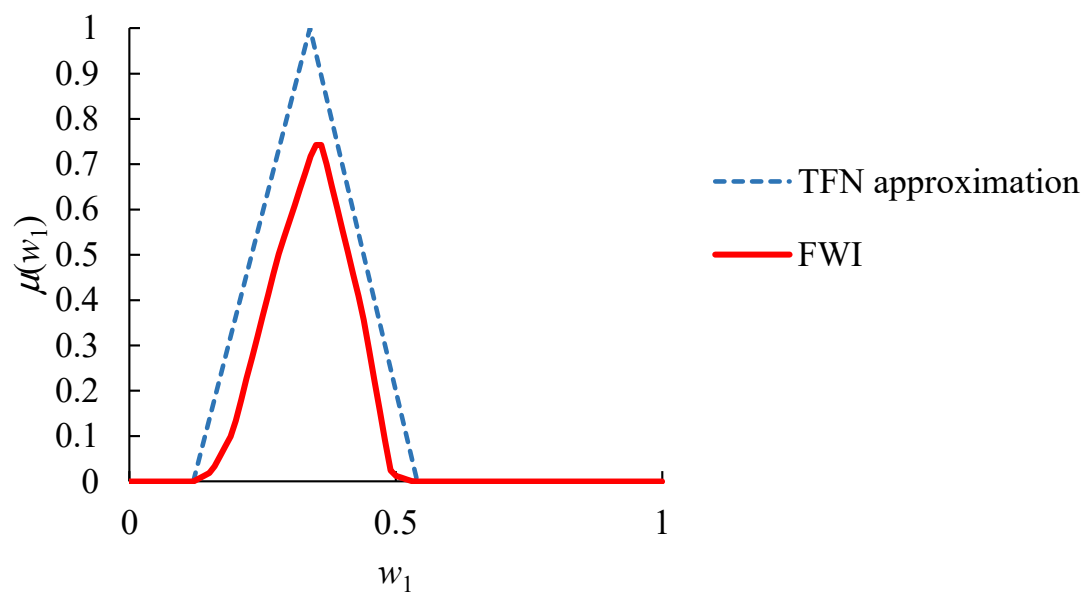

(a) Approximating the aggregation result of $\widetilde{w}_{1}$ with a TFN

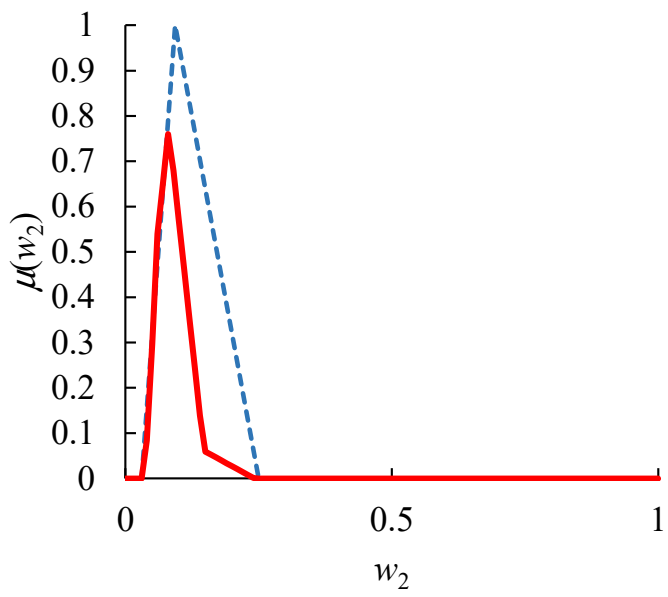

---. TFN approximation

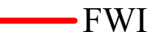

(b) Approximating the aggregation result of $\widetilde{w}_{2}$ with a TFN

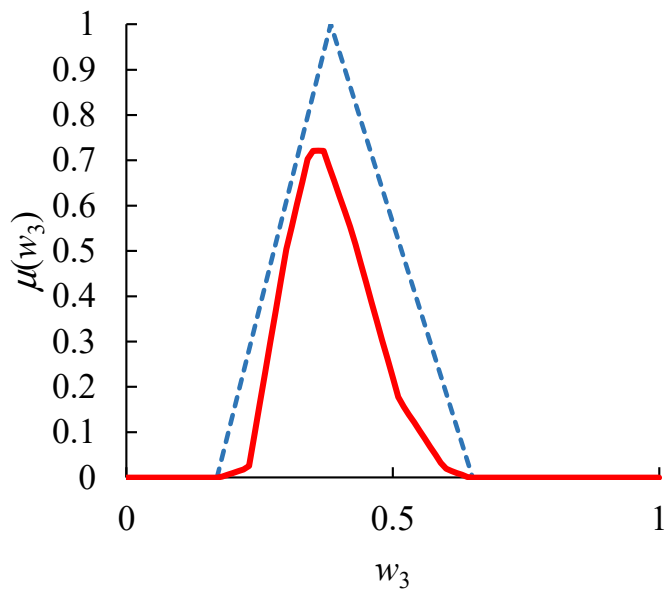

- - - TFN approximation

FWI

(c) Approximating the aggregation result of $\widetilde{w}_{3}$ with a TFN

Figure 7. Cont. 


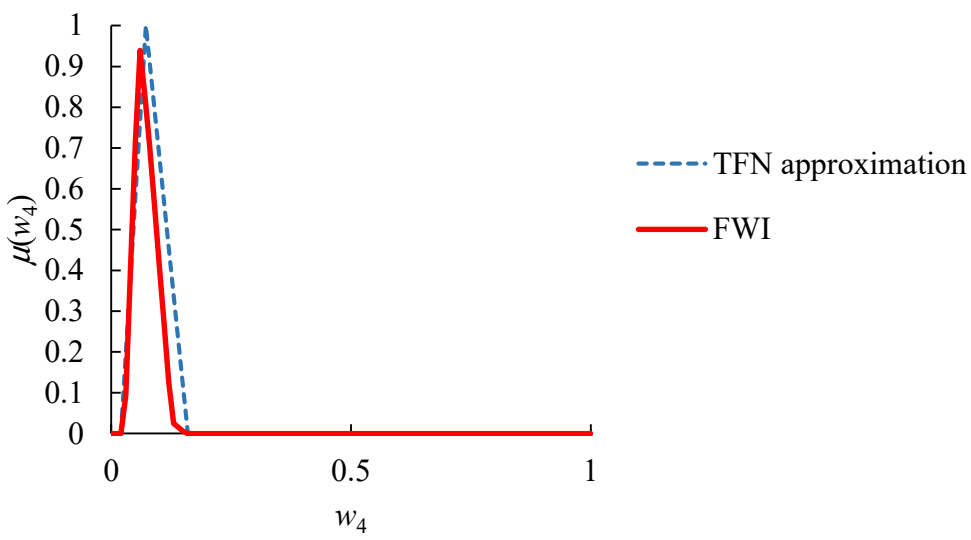

(d) Approximating the aggregation result of $\widetilde{w}_{4}$ with a TFN

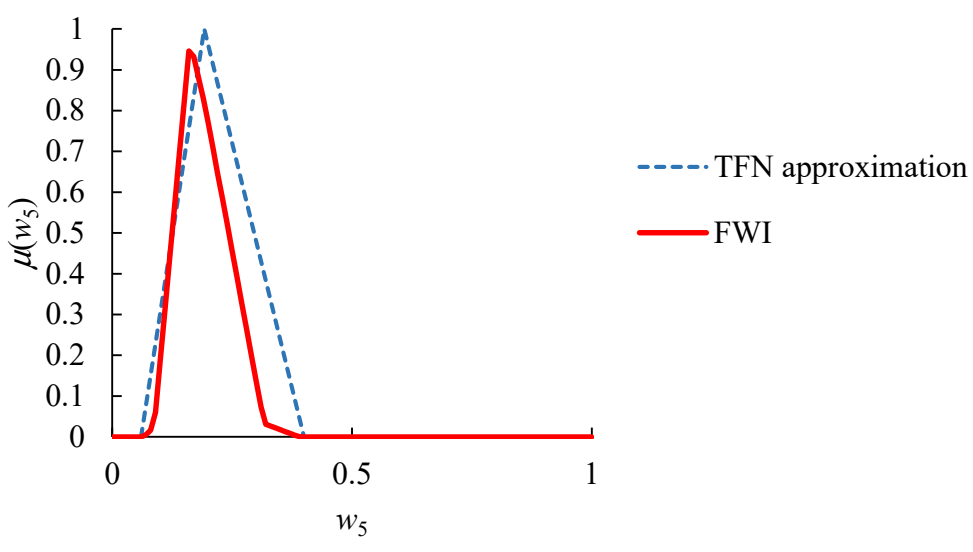

(e) Approximating the aggregation result of $\widetilde{w}_{5}$ with a TFN

Figure 7. Approximating the aggregation result with a TFN.

Fuzzy VIKOR was then applied to assess and compare the overall performances of four leisure agricultural parks. The details of these leisure agricultural parks are summarized in Table 2. The performance of a leisure agricultural park was evaluated according to the rules depicted in Table 3. The evaluation results are summarized in Table 4. There was no perfect alternative.

Table 2. Leisure agricultural park details.

\begin{tabular}{|c|c|c|c|c|c|c|}
\hline$h$ & Area $\left(\mathrm{m}^{2}\right)$ & $\begin{array}{l}\text { Major Agricultural } \\
\text { Products }\end{array}$ & City & $\begin{array}{l}\text { Number of } \\
\text { Confirmed } \\
\text { COVID-19 Cases * }\end{array}$ & $\begin{array}{l}\text { Distance } \\
\text { (min) }\end{array}$ & Image \\
\hline 1 & $2,120,000$ & $\begin{array}{l}\text { Shiitake mushrooms, } \\
\text { flowers }\end{array}$ & Taichung & 202 & 57 & $\begin{array}{l}\text { - Fresh air, rich natural ecology, } \\
\text { suitable for hiking }\end{array}$ \\
\hline 2 & 23,000 & Strawberry & Miaoli & 549 & 64 & $\begin{array}{l}\text { - Easy fruit picking, only sea- } \\
\text { sonal }\end{array}$ \\
\hline 3 & 145,000 & Orange, pitaya & Yunlin & 22 & 54 & - Cheap, time-consuming \\
\hline 4 & 500,000 & $\begin{array}{l}\text { Milk, dairy products, } \\
\text { malt }\end{array}$ & Miaoli & 549 & 57 & $\begin{array}{l}\text { - Abundant agricultural prod- } \\
\text { ucts and leisure activities, } \\
\text { suitable for hiking }\end{array}$ \\
\hline
\end{tabular}

*: Since 1 January 2021. 
Table 3. Rules for evaluating the performance of a leisure agricultural park.

\section{Criterion}

Image of the leisure agricultural park

\section{Rule}

$$
\widetilde{p}_{h 1}\left(x_{h 1}\right)=\left\{\begin{array}{ccc}
(0,0,1) & \text { if } & x_{h 1}=\text { "not very interesting (just for killing time)" } \\
(0,1,2) & \text { if } & x_{h 1}=\text { "somewhat interesting" } \\
(1.5,2.5,3.5) & \text { if } & x_{h 1}=\text { "interesting and somewhat healthy" } \\
(3,4,5) & \text { if } & x_{h 1}=\text { "interesting and healthy" } \\
(4,5,5) & \text { if } & x_{h 1}=\text { "very interesting and healthy (enjoyable)" }
\end{array}\right.
$$

where $x_{h 1}$ is the image of the leisure agricultural park.

Number of confirmed COVID-19 cases in the city

Easiness to maintain social distance

Distance to the leisure agricultural park
$0.1 \cdot \min x_{r 2}+0.9 \cdot \max _{r} x_{r 2}<x_{h 2}$

$(0,1,2) \quad$ if $\quad 0.35 \cdot \min _{r} x_{r 2}+0.65 \cdot \max _{r}^{r} x_{r 2} \leq x_{h 2}<0.1 \cdot \min _{r} x_{r 2}+0.9 \cdot \max _{r} x_{r 2}$

$(1.5,2.5,3.5)$ if $\quad 0.65 \cdot \min _{r}^{r} x_{r 2}+0.35 \cdot \max _{r}^{r} x_{r 2} \leq x_{h 2}<0.35 \cdot \min _{r}^{r} x_{r 2}+0.65 \cdot \max _{r}^{r} x_{r 2}$

$(3,4,5) \quad$ if $\quad 0.9 \cdot \min _{r}^{r} x_{r 2}+0.1 \cdot \max _{r}^{r} x_{r 2} \leq x_{h 2}<0.65 \cdot \min _{r}^{r} x_{r 2}+0.35 \cdot \max _{r}^{r} x_{r 2}$

$(4,5,5) \quad$ if $\quad r \quad x_{h 2} \leq 0.9 \cdot \min _{r} x_{r 2}+0.1 \cdot \max _{r}^{r} x_{r 2}$

where $x_{h 2}$ is the number of confirmed COVID-19 cases in the city.
$(0,0,1) \quad$ if $\quad x_{h 3} \leq 0.9 \cdot \min _{r} x_{r 3}+0.1 \cdot \max _{r} x_{r 3}$

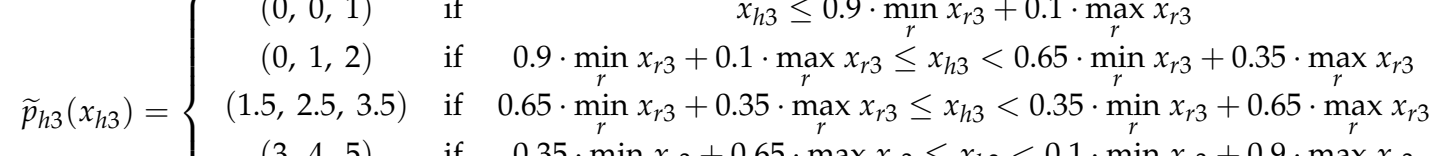

$(3,4,5) \quad$ if $\quad 0.35 \cdot \min _{r}^{r} x_{r 3}+0.65 \cdot \max _{r}^{r} x_{r 3} \leq x_{h 3}<0.1 \cdot \min _{r}^{r} x_{r 3}+0.9 \cdot \max _{r}^{r} x_{r 3}$

$(4,5,5) \quad$ if $\quad 0.1 \cdot \min _{r}^{r} x_{r 3}+0.9 \cdot \max _{r} x_{r 3}<x_{h 3}$

where $x_{h 3}$ is the area of the leisure agricultural park.

$(0,0,1) \quad$ if $\quad 0.1 \cdot \min _{r} x_{r 4}+0.9 \cdot \max _{r} x_{r 4}<x_{h 4}$

$\tilde{p}_{h 4}\left(x_{h 4}\right)=\left\{\begin{array}{ccc}(0,1,2) & \text { if } & 0.35 \cdot \min _{r} x_{r 4}+0.65 \cdot \max _{r} x_{r 4} \leq x_{h 4}<0.1 \cdot \min _{r} x_{r 4}+0.9 \cdot \max _{r} x_{r 4} \\ (1.5,2.5,3.5) & \text { if } & 0.65 \cdot \min _{r} x_{r 4}+0.35 \cdot \max _{r} x_{r 4} \leq x_{h 4}<0.35 \cdot \min _{r} x_{r 4}+0.65 \cdot \max _{r} x_{r 4} \\ (3,4,5) & \text { if } & 0.9 \cdot \min x_{r 4}+0.1 \cdot \max _{r 4} x_{r 4} \leq x_{h 4}<0.65 \cdot \min x_{r 4}+0.35 \cdot \max x_{r 4}\end{array}\right.$

$(3,4,5) \quad$ if $\quad 0.9 \cdot \min _{r}^{r} x_{r 4}+0.1 \cdot \max _{r}^{r} x_{r 4} \leq x_{h 4}<0.65 \cdot \min _{r}^{r} x_{r 4}+0.35 \cdot \max _{r}^{r} x_{r 4}$

$(4,5,5) \quad$ if $\quad x_{h 4} \leq 0.9 \cdot \min _{r} x_{r 4}+0.1 \cdot \max _{r} x_{r 4}$

where $x_{h 4}$ is the distance to the leisure agricultural park.

Preference for the leisure agricultural park

$(0,0,1) \quad$ if $\quad x_{h 1}=$ "very lowly preferred"

$\widetilde{p}_{h 5}\left(x_{h 5}\right)=\left\{\begin{array}{ccc}(0,0,1) & \text { if } & x_{h 1}=\text { "very lowly preferred" } \\ (0,1,2) & \text { if } & x_{h 1}=\text { "lowly preferred" } \\ (1.5,2.5,3.5) & \text { if } & x_{h 1}=\text { "moderately preferred" } \\ (3,4,5) & \text { if } & x_{h 1}=\text { "highly preferred" } \\ (4,5,5) & \text { if } & x_{h 1}=\text { "very highly preferred" }\end{array}\right.$

where $x_{h 5}$ is the preference for the leisure agricultural park. 
Table 4. Performances of the leisure agricultural parks.

\begin{tabular}{cccccc}
\hline $\boldsymbol{h}$ & $\widetilde{p}_{h 1}$ & $\widetilde{p}_{h 2}$ & $\widetilde{p}_{h 3}$ & $\widetilde{p}_{h 4}$ & $\widetilde{p}_{h 5}$ \\
\hline 1 & $(4,5,5)$ & $(3,4,5)$ & $(4,5,5)$ & $(0,1,2)$ & $(1.5,2.5,3.5)$ \\
\hline 2 & $(3,4,5)$ & $(0,0,1)$ & $(0,0,1)$ & $(4,5,5)$ & $(3,4,5)$ \\
\hline 3 & $(1.5,2.5,3.5)$ & $(4,5,5)$ & $(0,0,1)$ & $(0,0,1)$ & $(0,1,2)$ \\
\hline 4 & $(3,4,5)$ & $(0,0,1)$ & $(0,1,2)$ & $(0,1,2)$ & $(4,5,5)$ \\
\hline
\end{tabular}

Subsequently, the best and worst performances in optimizing each criterion were determined. The results are shown in Table 5.

Table 5. Best and worst performances in optimizing each criterion.

\begin{tabular}{cccccc}
\hline $\mathbf{i}$ & $\mathbf{1}$ & $\mathbf{2}$ & $\mathbf{3}$ & $\mathbf{4}$ & $\mathbf{5}$ \\
\hline$\widetilde{p}_{i}^{*}$ & $(4,5,5)$ & $(4,5,5)$ & $(4,5,5)$ & $(4,5,5)$ & $(4,5,5)$ \\
\hline$\widetilde{p}_{i}^{-}$ & $(1.5,2.5,3.5)$ & $(0,0,1)$ & $(0,1,2)$ & $(0,0,1)$ & $(0,1,2)$ \\
\hline
\end{tabular}

The normalized fuzzy distance between each leisure agricultural park and the best performance were measured. The measurement results are summarized in Table 6.

Table 6. Normalized fuzzy distance between each leisure agricultural park and the best performance.

\begin{tabular}{cccccc}
\hline $\boldsymbol{h}$ & $\widetilde{\boldsymbol{d}}_{\boldsymbol{h} 1}$ & $\widetilde{\boldsymbol{d}}_{\boldsymbol{h} 2}$ & $\widetilde{\boldsymbol{d}}_{\boldsymbol{h} 3}$ & $\widetilde{\boldsymbol{d}}_{\boldsymbol{h} 4}$ & $\widetilde{\boldsymbol{d}}_{\boldsymbol{h} 5}$ \\
\hline 1 & $(0,0,0.29)$ & $(0,0.2,0.4)$ & $(0,0,0.2)$ & $(0.4,0.8,1)$ & $(0.1,0.5,0.7)$ \\
\hline 2 & $(0,0.29,0.57)$ & $(0.6,1,1)$ & $(0.6,1,1)$ & $(0,0,0.2)$ & $(0,0.2,0.4)$ \\
\hline 3 & $(0.14,0.71,1)$ & $(0,0,0.2)$ & $(0.6,1,1)$ & $(0.6,1,1)$ & $(0.4,0.8,1)$ \\
\hline 4 & $(0,0.29,0.57)$ & $(0.6,1,1)$ & $(0.4,0.8,1)$ & $(0.4,0.8,1)$ & $(0,0,0.2)$ \\
\hline
\end{tabular}

The values of $\widetilde{S}_{h}$ and $\widetilde{R}_{h}$ were then computed for each leisure agricultural park. The results are summarized in Table 7 . Based on them, the $\widetilde{Q}_{h}$ of the leisure agricultural park was derived by setting $\xi$ to 0.5 .

Table 7. The $\widetilde{S}_{h}, \widetilde{R}_{h}$ and $\widetilde{Q}_{h}$ of each leisure agricultural park.

\begin{tabular}{cccc}
\hline $\boldsymbol{h}$ & $\widetilde{\boldsymbol{S}}_{\boldsymbol{h}}$ & $\widetilde{\boldsymbol{R}}_{\boldsymbol{h}}$ & $\widetilde{\boldsymbol{Q}}_{\boldsymbol{h}}$ \\
\hline 1 & $(0.01,0.17,0.82)$ & $(0.01,0.1,0.28)$ & $(0,0,0.44)$ \\
\hline 2 & $(0.12,0.61,1.4)$ & $(0.1,0.38,0.65)$ & $(0,0.35,0.89)$ \\
\hline 3 & $(0.16,0.85,1.8)$ & $(0.1,0.38,0.65)$ & $(0,0.41,1)$ \\
\hline 4 & $(0.09,0.55,1.45)$ & $(0.07,0.31,0.65)$ & $(0,0.27,0.9)$ \\
\hline
\end{tabular}

The defuzzified values of these performance measures are summarized in Table 8. Based on the defuzzification results, the leisure agricultural parks were ranked, as shown in Table 8. Leisure agricultural park \#1 achieved the lowest value of $\widetilde{Q}_{h}$, followed by leisure agricultural park \#4. 
Table 8. Defuzzification results.

\begin{tabular}{ccccc}
\hline $\boldsymbol{H}$ & $\boldsymbol{D}\left(\widetilde{\boldsymbol{S}}_{\boldsymbol{h}}\right)$ & $\boldsymbol{D}\left(\widetilde{\boldsymbol{R}}_{\boldsymbol{h}}\right)$ & $\boldsymbol{D}\left(\widetilde{\boldsymbol{Q}}_{\boldsymbol{h}}\right)$ & Rank \\
\hline 1 & 0.296 & 0.120 & 0.110 & 1 \\
\hline 2 & 0.686 & 0.380 & 0.395 & 3 \\
\hline 3 & 0.914 & 0.380 & 0.457 & 4 \\
\hline 4 & 0.663 & 0.333 & 0.361 & 2 \\
\hline
\end{tabular}

\subsection{Discussion}

According to the results of the case study, the following discussion was presented:

(1) The most suitable leisure agricultural park for the family was leisure agricultural park $\# 1$; it had the best image and was the easiest to maintain social distance.

(2) However, the superiority of leisure agricultural park \#1 over leisure agricultural park \#4 only met the second condition. Therefore, both leisure agricultural parks could be recommended to the family for their consideration.

(3) In contrast, leisure agricultural park \#3 ranked last because the family showed the lowest preference for this leisure agricultural park.

(4) A parametric analysis has been conducted to examine the effect of $\xi$ on the ranking result. The results are summarized in Table 9. The superiority of leisure agricultural park \#1 over the others was not affected by the value of $\xi$. In addition, when $\xi$ was set to zero, there was a tie between leisure agricultural parks \#2 and \#3.

Table 9. Results of the parametric analysis.

\begin{tabular}{cc}
\hline$\xi$ & Ranking Result \\
\hline 0 & $1 \rightarrow 4 \rightarrow 2,3$ \\
\hline 0.1 & $1 \rightarrow 4 \rightarrow 2 \rightarrow 3$ \\
\hline 0.2 & $1 \rightarrow 4 \rightarrow 2 \rightarrow 3$ \\
\hline 0.3 & $1 \rightarrow 4 \rightarrow 2 \rightarrow 3$ \\
\hline 0.4 & $1 \rightarrow 4 \rightarrow 2 \rightarrow 3$ \\
\hline 0.5 & $1 \rightarrow 4 \rightarrow 2 \rightarrow 3$ \\
\hline 0.6 & $1 \rightarrow 4 \rightarrow 2 \rightarrow 3$ \\
\hline 0.7 & $1 \rightarrow 4 \rightarrow 2 \rightarrow 3$ \\
\hline 0.8 & $1 \rightarrow 4 \rightarrow 2 \rightarrow 3$ \\
\hline 0.9 & $1 \rightarrow 4 \rightarrow 2 \rightarrow 3$ \\
\hline 1.0 & $1 \rightarrow 4 \rightarrow 2 \rightarrow 3$ \\
\hline
\end{tabular}

(1) The recommendation results to ten traveler groups and their choices are summarized in Table 10. As a result, the successful recommendation rate was $90 \%$, high enough to support the effectiveness of the proposed methodology.

(2) Among the ten traveler groups, seven rated the easiness to maintain social distance as the most important criterion. In contrast, the distance to a leisure agricultural park was considered the least important criterion by most traveler groups. 
Table 10. Recommendation results to ten traveler groups.

\begin{tabular}{ccc}
\hline Group \# & Recommendation & Choice \\
\hline 1 & Leisure agricultural park \#1 & Leisure agricultural park \#1 \\
\hline 2 & Leisure agricultural park \#5 & Leisure agricultural park \#5 \\
\hline 3 & Leisure agricultural park \#4 & Leisure agricultural park \#4 \\
\hline 4 & Leisure agricultural park \#6 & Leisure agricultural park \#6 \\
\hline 5 & Leisure agricultural park \#1 & Leisure agricultural park \#1 \\
\hline 6 & Leisure agricultural park \#11 & Leisure agricultural park \#11 \\
\hline 7 & Leisure agricultural park \#2 & Leisure agricultural park \#3 \\
\hline 8 & Leisure agricultural park \#9 & Leisure agricultural park \#9 \\
\hline 9 & Leisure agricultural park \#1 & Leisure agricultural park \#1 \\
\hline 10 & Leisure agricultural park \#11 & Leisure agricultural park \#11
\end{tabular}

(1) Three existing fuzzy group decision-making methods were also applied to this case for comparison. The first was the FGM-FGM-fuzzy weighted average (FWA) method, in which the decision makers' fuzzy judgement matrixes were aggregated using FGM. Then, the fuzzy priorities of criteria were derived using FGM. Finally, the overall performance of each leisure agricultural park was evaluated using FWA. The second method was the FGM-FEA-FWA method, wherein FEA [31] was applied to derive the priorities of criteria in place of the FGM method. The third method was the FGMFGM-FTOPSIS method, which was similar to the FGM-FGM-FWA method, except that fuzzy TOPSIS was employed to compare the overall performances of leisure agricultural parks. The results obtained using these methods are summarized in Table 11. It can be observed that the ranking results of leisure agricultural parks using existing methods were different from those using the proposed methodology, which is due to the imprecision of these existing methods in deriving the fuzzy priorities of criteria; for example, the fuzzy priorities of criterion $\widetilde{w}_{5}$ derived by decision maker \#1 using various methods are compared in Table 12, showing a significant difference between these results.

Table 11. Ranking results using existing methods.

\begin{tabular}{ccccc}
\hline$h$ & $\begin{array}{c}\text { Rank } \\
\text { (FGM-FGM- } \\
\text { FWA) }\end{array}$ & $\begin{array}{c}\text { Rank } \\
\text { (FGM-FEA-FWA) }\end{array}$ & $\begin{array}{c}\text { Rank } \\
\text { (FGM-FGM- } \\
\text { FTOPSIS) }\end{array}$ & $\begin{array}{c}\text { Rank } \\
\text { (Proposed } \\
\text { Methodology) }\end{array}$ \\
\hline 1 & 1 & 1 & 1 & 1 \\
\hline 2 & 2 & 2 & 2 & 3 \\
\hline 3 & 4 & 4 & 4 & 4 \\
\hline 4 & 3 & 3 & 3 & 2 \\
\hline
\end{tabular}

Table 12. Fuzzy priorities of criterion $\widetilde{w}_{5}$ derived by decision maker $\# 1$ using various methods.

\begin{tabular}{cc}
\hline Method & $\widetilde{\boldsymbol{w}}_{5}$ \\
\hline FGM & $(0.079,0.157,0.309)$ \\
\hline FEA & 0.257 \\
\hline acFGM & $(0.087,0.165,0.316)$ \\
\hline
\end{tabular}

\section{Conclusions}

Visiting leisure agricultural parks has always been an activity for people to relax and pursue health [43-46], especially during the COVID-19 pandemic. At the beginning of 
the pandemic, people were hesitant to go to leisure agricultural parks for fear of being infected. With the increasing popularity of vaccines, people began to resume this leisure activity. However, during the COVID-19 pandemic, many uncertain factors make choosing a suitable leisure agricultural park a complicated decision, especially for traveler groups. To solve this problem, a fuzzy collaborative intelligence approach is proposed in this study. In the proposed methodology, first, the acFGM method is devised to derive the fuzzy priorities of criteria. Subsequently, FWI is applied to aggregate the fuzzy priorities derived by all decision makers to consider their unequal levels of authority. Based on the aggregation result, the fuzzy VIKOR method is applied to compare the overall performances of leisure agricultural parks.

The proposed methodology has been applied to a case study to examine its effectiveness. The results of the case study are reported as follows:

(1) During the COVID-19 pandemic, the willingness of travelers (especially traveler groups) to go to a leisure agricultural park was quite high.

(2) In choosing a suitable leisure agricultural park, the most important criterion was the easiness to maintain social distance, while the least important criterion was the distance to a leisure agricultural park.

(3) Nine of ten traveler groups followed the recommendations, resulting in a successful recommendation rate of $90 \%$.

The methodology proposed in this research has the following limitations:

(1) The easiness to maintain social distance is directly proportional to the area of a leisure agricultural park. Although such an evaluation method is simple, it may not be practical because in a leisure agricultural park, travelers will only go to part of the area.

(2) Although it is not difficult to write a program to implement the proposed methodology, the proposed methodology is slightly more complicated than some multi-criteria decision-making methods for similar purposes.

After the COVID-19 outbreak, many agricultural activities have encountered difficulties and must change; for example, in response to the shortage of manpower supply, should a farmland owner purchase automated agricultural machinery or change the agricultural products to reduce manpower requirements? The methodology proposed in this study can be applied to make these decisions. In addition, this study applies FWI to aggregate the preferences of decision makers with unequal levels of authority. In future research, different methods can also be proposed to fulfill the same purpose. These constitute some directions for future research.

Author Contributions: All authors equally contributed to the writing of this paper. Data curation, methodology and writing original draft: T.-C.T.C. and H.-C.W.; writing-review and editing: T.-C.T.C., H.-C.W. and Y.-C.L. All authors have read and agreed to the published version of the manuscript.

Funding: This research received no external funding.

Institutional Review Board Statement: Not applicable.

Informed Consent Statement: Informed consent was obtained from all subjects involved in the study.

Acknowledgments: This work was supported by ministry of science of technology of Taiwan.

Conflicts of Interest: The authors declare no conflict of interest.

\section{References}

1. Zhong, L.; Sun, S.; Law, R.; Li, X. Tourism crisis management: Evidence from COVID-19. Curr. Issues Tour. 2021, 24, 2671-2682. [CrossRef]

2. Schmöcker, J.D. Estimation of city tourism flows: Challenges, new data and COVID. Transp. Rev. 2021, 41, 137-140. [CrossRef]

3. Qiao, L.; Zhou, K.; Zhang, Y. From seed to feed: Organic food leisure park construction. Nat. Environ. Pollut. Technol. 2014, 13, 429. 
4. Li, Z.; Zhang, X.; Yang, K.; Singer, R.; Cui, R. Urban and rural tourism under COVID-19 in China: Research on the recovery measures and tourism development. Tour. Rev. 2021, 76, 718-736. [CrossRef]

5. Lin, T.C.; Pao, T.P. Leisure activities' selection and motivation. Int. J. Acad. Res. Bus. Soc. Sci. 2011, 1, 308.

6. Huang, C.M.; Tuan, C.L.; Wongchai, A. Development analysis of leisure agriculture-A case study of Longjing Tea Garden, Hangzhou, China. APCBEE Procedia 2014, 8, 210-215. [CrossRef]

7. Puvača, N.; Lika, E.; Brkanlić, S.; Breso, E.; Ilić, D.; Kika, T.S.; Brkić, I. The pandemic of SARS-CoV-2 as a worldwide health safety risk. J. Agron. Technol. Eng. Manag. 2021, 4, 523-532.

8. Sivan, A. Leisure in times of COVID-19: Reflection on Hong Kong and Israel. World Leis. J. 2020, 62, 322-324. [CrossRef]

9. Du, J.; Floyd, C.; Kim, A.C.; Baker, B.J.; Sato, M.; James, J.D.; Funk, D.C. To be or not to be: Negotiating leisure constraints with technology and data analytics amid the COVID-19 pandemic. Leis. Stud. 2021, 40, 561-574. [CrossRef]

10. Hsiao, C.Y.; Tuan, C.L. How recreational farm operators use dynamic capabilities to respond outbreak of COVID-19 pandemic. J. Outdoor Recreat. Tour. 2021, 100460. [CrossRef]

11. Pan, D.; Yang, J.; Zhou, G.; Kong, F. The influence of COVID-19 on agricultural economy and emergency mitigation measures in China: A text mining analysis. PLoS ONE 2020, 15, e0241167. [CrossRef] [PubMed]

12. Ateljevic, I. Transforming the (tourism) world for good and (re)generating the potential 'new normal'. Tour. Geogr. 2020, 22, 467-475. [CrossRef]

13. Putian, G. Analysis of the impacts of COVID-19 pandemic on leisure agriculture and rural tourism in Zhengzhou and the countermeasures. Front. Soc. Sci. Technol. 2020, 2, 89-96.

14. Barrot, J.-N.; Basile, G.; Sauvagnat, J. Sectoral effects of social distancing. Covid Econ. Cent. Econ. Policy Res. 2020, 3, 85-102. [CrossRef]

15. Feuerbacher, A.; McDonald, S.; Thierfelder, K. Peasant farmers and pandemics: The role of seasonality and labor-leisure trade-off decisions in economy-wide models. Econ. Syst. Res. 2021. [CrossRef]

16. Langemeyer, J.; Madrid-Lopez, C.; Beltran, A.M.; Mendez, G.V. Urban agriculture-A necessary pathway towards urban resilience and global sustainability? Landsc. Urban Plan. 2021, 210, 104055. [CrossRef]

17. Saaty, T.L. Decision making with the analytic hierarchy process. Int. J. Serv. Sci. 2008, 1, 83-98. [CrossRef]

18. Zheng, G.; Zhu, N.; Tian, Z.; Chen, Y.; Sun, B. Application of a trapezoidal fuzzy AHP method for work safety evaluation and early warning rating of hot and humid environments. Saf. Sci. 2012, 50, 228-239. [CrossRef]

19. Chen, T.; Wang, Y.C. A calibrated piecewise-linear FGM approach for travel destination recommendation during the COVID-19 pandemic. Appl. Soft Comput. 2021, 109, 107535. [CrossRef]

20. Chen, T.C.T.; Wang, Y.C.; Lin, C.W. A fuzzy collaborative forecasting approach considering experts' unequal levels of authority. Appl. Soft Comput. 2020, 94, 106455. [CrossRef]

21. Wei, G. Some induced geometric aggregation operators with intuitionistic fuzzy information and their application to group decision making. Appl. Soft Comput. 2010, 10, 423-431. [CrossRef]

22. Xia, M.; Xu, Z.; Chen, N. Some hesitant fuzzy aggregation operators with their application in group decision making. Group Decis. Negot. 2013, 22, 259-279. [CrossRef]

23. Ashraf, S.; Abdullah, S. Spherical aggregation operators and their application in multiattribute group decision-making. Int. J. Intell. Syst. 2019, 34, 493-523. [CrossRef]

24. Wu, H.C.; Chen, T.C.T.; Huang, C.H.; Shih, Y.C. Comparing built-in power banks for a smart backpack design using an auto-weighting fuzzy-weighted-intersection FAHP approach. Mathematics 2020, 8, 1759. [CrossRef]

25. Van Broekhoven, E.; De Baets, B. Fast and accurate center of gravity defuzzification of fuzzy system outputs defined on trapezoidal fuzzy partitions. Fuzzy Sets Syst. 2006, 157, 904-918. [CrossRef]

26. Qin, J.; Liu, X.; Pedrycz, W. An extended VIKOR method based on prospect theory for multiple attribute decision making under interval type-2 fuzzy environment. Knowl. -Based Syst. 2015, 86, 116-130. [CrossRef]

27. Wang, H.; Pan, X.; He, S. A new interval type-2 fuzzy VIKOR method for multi-attribute decision making. Int. J. Fuzzy Syst. 2019, 21, 145-156. [CrossRef]

28. Opricovic, S. Fuzzy VIKOR with an application to water resources planning. Expert Syst. Appl. 2011, 38, 12983-12990. [CrossRef]

29. Chen, T. A FAHP-FTOPSIS approach for choosing mid-term occupational healthcare measures amid the COVID-19 pandemic. Health Policy Technol. 2021, 10, 100517. [CrossRef]

30. Zandi, P.; Rahmani, M.; Khanian, M.; Mosavi, A. Agricultural risk management using fuzzy TOPSIS analytical hierarchy process (AHP) and failure mode and effects analysis (FMEA). Agriculture 2020, 10, 504. [CrossRef]

31. Chang, D.Y. Applications of the extent analysis method on fuzzy AHP. Eur. J. Oper. Res. 1996, 95, 649-655. [CrossRef]

32. Chen, T.C.T. Evaluating the sustainability of a smart technology application to mobile health care: The FGM-ACO-FWA approach. Complex Intell. Syst. 2020, 6, 109-121. [CrossRef]

33. Chen, T.; Lin, Y.C.; Chiu, M.C. Approximating alpha-cut operations approach for effective and efficient fuzzy analytic hierarchy process analysis. Appl. Soft Comput. 2019, 85, 105855. [CrossRef]

34. Demirel, N.Ç.; Yücenur, G.N.; Demirel, T.; Muşdal, H. Risk-based evaluation of Turkish agricultural strategies using fuzzy AHP and fuzzy ANP. Hum. Ecol. Risk Assess. Int. J. 2012, 18, 685-702. [CrossRef]

35. Wang, B.; Song, J.; Ren, J.; Li, K.; Duan, H. Selecting sustainable energy conversion technologies for agricultural residues: A fuzzy AHP-VIKOR based prioritization from life cycle perspective. Resour. Conserv. Recycl. 2019, 142, 78-87. [CrossRef] 
36. Amini, S.; Rohani, A.; Aghkhani, M.H.; Abbaspour-Fard, M.H.; Asgharipour, M.R. Assessment of land suitability and agricultural production sustainability using a combined approach (Fuzzy-AHP-GIS): A case study of Mazandaran province, Iran. Inf. Process. Agric. 2020, 7, 384-402. [CrossRef]

37. Tashayo, B.; Honarbakhsh, A.; Azma, A.; Akbari, M. Combined fuzzy AHP-GIS for agricultural land suitability modeling for a watershed in southern Iran. Environ. Manag. 2020, 66, 364-376. [CrossRef]

38. Chen, T.; Wang, Y.C. Recommending suitable smart technology applications to support mobile healthcare after the COVID-19 pandemic using a fuzzy approach. Healthcare 2021, 9, 1461. [CrossRef] [PubMed]

39. Sharif, M.; Khan, M.A.; Iqbal, Z.; Azam, M.F.; Lali, M.I.U.; Javed, M.Y. Detection and classification of citrus diseases in agriculture based on optimized weighted segmentation and feature selection. Comput. Electron. Agric. 2018, 150, 220-234. [CrossRef]

40. Chen, T.; Wang, Y.C.; Wu, H.C. Analyzing the impact of vaccine availability on alternative supplier selection amid the COVID-19 pandemic: A cFGM-FTOPSIS-FWI approach. Healthcare 2021, 9, 71. [CrossRef] [PubMed]

41. Mendas, A.; Delali, A. Support system based on GIS and weighted sum method for drawing up of land suitability map for agriculture. Application to durum wheat cultivation in the area of Mleta (Algeria). Span. J. Agric. Res. 2012, 1, 34-43.

42. Wu, H.C.; Wang, Y.C.; Chen, T.C.T. Assessing and comparing COVID-19 intervention strategies using a varying partial consensus fuzzy collaborative intelligence approach. Mathematics 2020, 8, 1725. [CrossRef]

43. Chiu, M.C.; Chen, T. Assessing mobile and smart technology applications for active and healthy aging using a fuzzy collaborative intelligence approach. Cogn. Comput. 2021, 13, 431-446. [CrossRef]

44. Wojcieszak-Zbierska, M.M.; Jęczmyk, A.; Zawadka, J.; Uglis, J. Agritourism in the era of the coronavirus (COVID-19): A rapid assessment from Poland. Agriculture 2020, 10, 397. [CrossRef]

45. Chen, T. A fuzzy ubiquitous traveler clustering and hotel recommendation system by differentiating travelers' decision-making behaviors. Appl. Soft Comput. 2020, 96, 106585. [CrossRef]

46. Deshpande, A. The COVID-19 pandemic and gendered division of paid work, domestic chores and leisure: Evidence from India's first wave. Econ. Politica 2021. [CrossRef] 